\title{
Condom Use Among High-Risk Adolescents: Testing the Influence of Alcohol Use on the Relationship of Cognitive Correlates of Behavior
}

\author{
Angela Bryan and Courtney A. Rocheleau \\ University of Colorado at Boulder
}

\author{
Reuben N. Robbins \\ Fordham University
}

\author{
Kent E. Hutchison \\ University of Colorado at Boulder
}

\begin{abstract}
The goal of this study was the exploration of distal effects of alcohol use on condom use. Criminally involved adolescents completed an initial measure of attitudes, beliefs, and prior behavior. Of the 300 who completed the initial measurement, 267 (89\%) completed a behavioral assessment 6 months later. Analyses validated a theoretical model of condom use intentions and indicated that intentions and attitudes measured at baseline were significant predictors of condom use behavior 6 months later. Neither alcohol use nor alcohol problems moderated relationships among model variables or the influence of intentions and attitudes on behavior. The findings do not support a distal role for alcohol use in altering the cognitive correlates of condom use intentions and behavior among high-risk adolescents.
\end{abstract}

Keywords: high-risk adolescents, HIV/STD, alcohol use, alcohol problems, intentions

Because of high rates of unprotected intercourse with multiple partners, adolescents are at great risk for sexually transmitted diseases (STDs), including HIV (Centers for Disease Control and Prevention [CDC], 2000b; Whaley, 1999). Though the CDC (2000a) reports that overall AIDS incidence is on the decline, there has been no comparable decline in the number of newly diagnosed HIV cases among young people aged 13-19, and young people of color are particularly at risk. Further, the highest rates of many common STDs (e.g., chlamydia) occur in young people between the ages of 15 and 24 (CDC, 2000a). In comparison to the general adolescent population, adolescents involved with the criminal justice system are younger at first intercourse and have higher rates of anal intercourse, a greater number of sex partners, and lower rates of condom use (Barthlow, Horan, DiClemente, \& Lanier, 1995; DiClemente, 1992; Lux \& Petosa, 1995). Engaging in these risky sexual behaviors results in high rates of unintended pregnancy and STDs among criminally involved adolescents (Canterbury, Clavet, McGarvey, \& Koopman, 1998; Morris, Baker, Valentine, \& Pennisi, 1998; St. Lawrence, Crosby, Belcher, Yazdani, \& Brasfield, 1999).

Alcohol use is commonly cited as a reason for lack of condom use among these adolescents (Brook, Balka, Abernathy, \& Ham-

Angela Bryan, Department of Psychology and Institute of Behavioral Science, University of Colorado at Boulder; Courtney A. Rocheleau and Kent E. Hutchison, Department of Psychology, University of Colorado at Boulder; Reuben N. Robbins, Department of Psychology, Fordham University.

This study was supported by National Institute on Alcoholism and Alcohol Abuse Grant AA12925-01 to Angela Bryan.

Correspondence concerning this article should be addressed to Angela Bryan, Department of Psychology, Campus Box 345, University of Colorado, Boulder, CO 80309-0345. E-mail: angela.bryan@ colorado.edu burg, 1994; Lowry et al., 1994; Morris et al., 1998; Shafer et al., 1993), largely because they evidence extremely high levels of both alcohol use and risky sexual behavior. As described by HalpernFelsher, Millstein, and Ellen (1996), the association between alcohol and risky sexual behavior has primarily been examined via three types of studies in previous research: (a) global correlation, (b) situational covariation, and (c) event-level analysis.

In global correlation studies, participants are asked the frequency with which they use alcohol and the frequency with which they use condoms, and in general a positive relationship has been found (Halpern-Felsher et al., 1996). However, such studies suffer from numerous methodological limitations, chiefly that the general association between risky sex and alcohol use does not connect these two behaviors in time (Donovan \& McEwan, 1995). Situational covariation studies ask participants to recall their drinking behavior concurrent with sexual behavior over a specific period of time and their use of condoms over that same period of time, thus attempting to temporally associate drinking during sex and risky sexual behavior (e.g., Leigh \& Stall, 1993). Such studies are an improvement over global correlation studies yet still fail to establish that lack of condom use and drinking concurrent with sexual activity are occurring at the same intercourse episode.

Studies using an event analysis or episodic methodology, when they show an association between alcohol use and risky sexual behavior, are the most convincing evidence that alcohol use proximally influences condom use. In event analysis, participants are asked to recall a particular intercourse episode (e.g., most recent intercourse), whether they or their partner were using alcohol at the time, and whether a condom was used. The results of such studies have produced conflicting results (Leigh \& Stall, 1993; Weinhardt \& Carey, 2000). For example, Tubman and Langer (1995) found no significant association, whereas Dermen, Cooper, and Agocha (1998) found that alcohol use was positively associated with an 
HIV risk index at three intercourse occasions among a random sample of adolescents. The dependent measures of risk were not commensurate in these studies, a recurring problem in this area (Leigh \& Stall, 1993; Weinhardt \& Carey, 2000). Nevertheless, studies using event analysis have also not produced consistent findings of a reliable association between alcohol use and risky sex.

Perhaps one reason for the inconsistency is that all three of these methodologies make the implicit assumption that the influence of alcohol on risky sexual behavior occurs at the time of the intercourse episode. In other words, an individual's decision about condom use at the time of sexual intercourse is directly affected by alcohol intoxication. The assumption is made, but never tested, that regardless of alcohol use status everyone plans to use condoms but that those plans are thwarted by intoxication at the time of intercourse. Although this may very well be true, we assert that it is also possible that alcohol use affects the likelihood of condom use long before intercourse is imminent, it may affect cognitions relevant to development of intentions to use condoms, and it may consistently interfere with the intentions-behavior relationship. This study tested such hypotheses.
Namely, we tested whether alcohol exerts an influence on risky sexual behavior that is quite distal to the behavior itself, when individuals are forming intentions regarding condom use and sexual behavior. For example, a heavy alcohol user might, from prior experience, come to believe that condom use is difficult and too much trouble to deal with if he or she is drinking (i.e., decreased self-efficacy) or is simply not a behavior worth planning for (i.e., weak or nonexistent relationships among attitudes, self-efficacy, and intentions). It could also be that all the best of intentions to use condoms are compromised in sexual situations because of frequent alcohol use, so it might be that the intentions-behavior relationship holds for nondrinkers but not for drinkers. In order to examine these relationships, one must begin with a fully specified model of the relationships that exist among cognitive correlates, intentions, and behavior in a given population (see Figure 1) and then test the differential relationships and predictive validity of the model as a function of alcohol use.

The examination of these distal relationships has theoretical implications but is also important from the standpoint of intervention development. If the relationships in the model of intentions are weak or nonexistent for drinkers, then interventions to increase

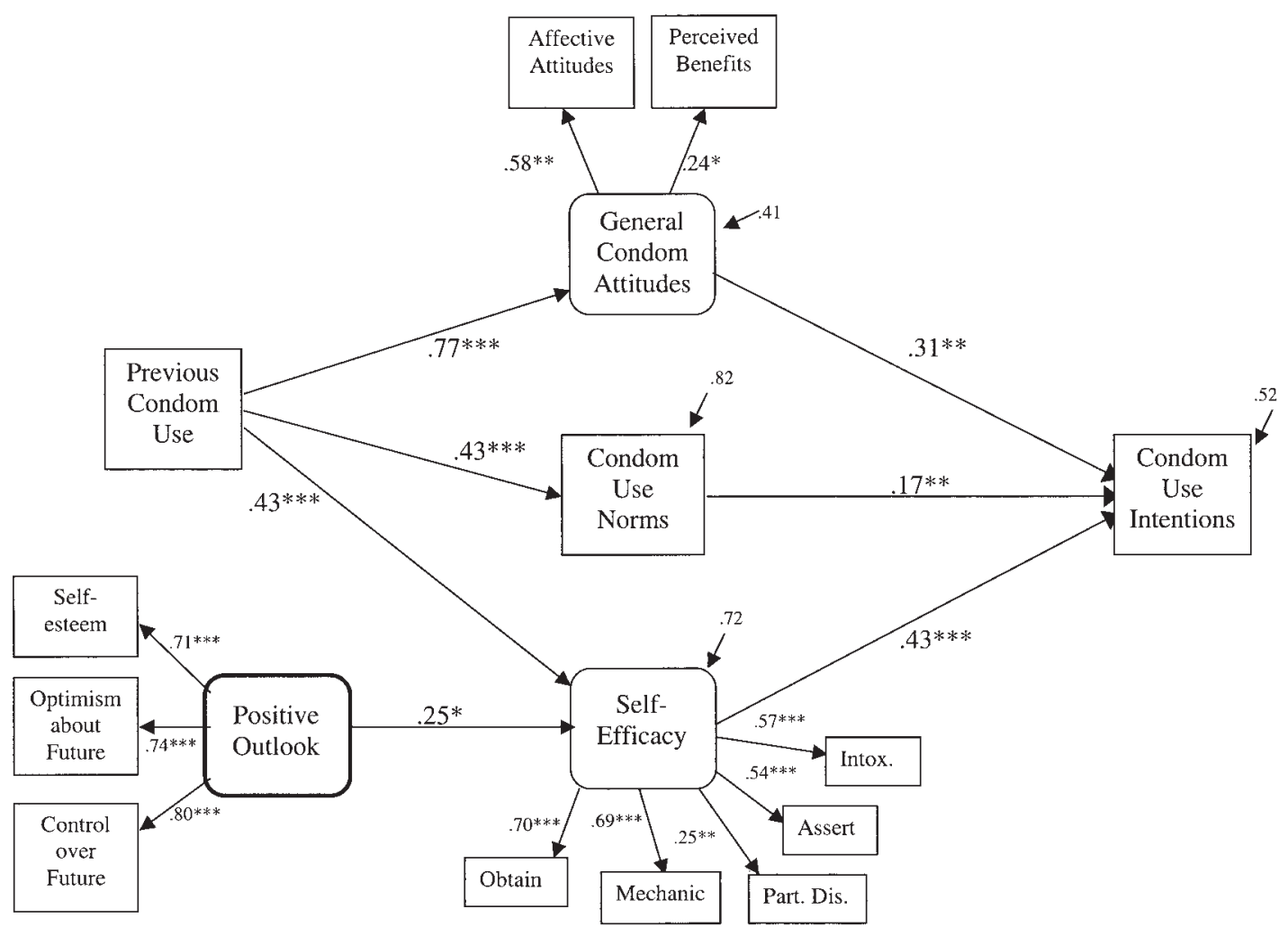

Figure 1. Model of condom use intentions among sexually experienced high-risk adolescents. Coefficients are standardized path coefficients. Correlated errors between assertiveness and intoxication and between mechanics and obtaining subscales of self-efficacy are estimated but not shown. Overall model fit: $\chi^{2}(59, N=230)=$ $155.74, p<.001$; comparative fit index $=.88$; root-mean-square error of approximation $($ RMSEA $)=.088 ; 90 \%$ confidence intervals of the RMSEA $=.07-.11$; standardized root-mean-square residual $=.098$. Intox. $=$ using condoms while under the influence; Part. Dis. = dealing with partner dissatisfaction. $* p<.05$. ** $p<.01$. $* * * p<.001$. 
condom use targeted to high-risk, alcohol-using adolescents that rely on such models are unlikely to be effective. A demonstration that alcohol use concurrent with sexual activity consistently interferes with the link between intention to use condoms and condom use would indicate that interventions should include a focus on the reduction of alcohol use at the event level, as opposed to a more global level, in order to increase condom use among alcohol-using adolescents.

The fully specified model that serves as the basis for this work appears in Figure 1. The development of this model capitalized on previous research (Bryan, Aiken, \& West, 1996, 1997, 2004; Bryan, Schindeldecker, \& Aiken, 2001) in which the authors developed psychosocial models of condom use intentions that are tailored to particular subpopulations. These models contain two classes of constructs: (a) general constructs from established models of health behavior (e.g., health belief model-Rosenstock, 1990; theory of planned behavior [TPB]—Ajzen \& Madden, 1986; social cognitive theory [SCT]—Bandura, 1992), and (b) subpopulation relevant constructs, which are critical to more limited sociodemographic groups. The model in Figure 1 includes subpopulation relevant constructs found to be especially relevant to highrisk adolescents (positive self-concept, positive orientation toward the future). These factors were significant correlates of general constructs (here, condom use self-efficacy) and define how levels of the general construct may accrue in this particular subpopulation.

The general predictors in our model have been validated in numerous empirical studies (e.g., Fazekas, Senn, \& Ledgerwood, 2001; Smith \& Stasson, 2000; Sutton, McVey, \& Glanz, 1999), though rarely if ever are such models tested with high-risk, ethnically diverse adolescent samples. In fact, we were able to locate only one study that tests any of the major models of health behavior (health belief model, SCT, theory of reasoned action [TRA]/TPB) in their entirety among high-risk, ethnically diverse adolescents (cf. Hutchinson, Jemmott, Jemmott, Braverman, \& Fong, 2003), and even that study was not without problems (e.g., single-item measures of SCT constructs). Though studies typically include constructs from the major models and test bivariate associations or even simultaneous prediction via regression (e.g., Koniak-Griffin, Lesser, Uman, \& Nyamathi, 2003; Laraque, McLean, Brown-Peterside, Ashton, \& Diamond, 1997; Rosengard et al., 2001), most are one-time cross-sectional assessments, do not include any assessments of behavior, and leave hypothesized mediational relationships untested. We feel it is crucial that the full models be tested, including all of these hypothesized mediational relationships and prospective assessments of behavior, before these models are deemed to work for a specific population and behavior. Assuming that these models are one size fits all in terms of both the population and the behavior can lead to intervention content that is not articulated to the population at focus. For example, in a recent work, Bryan, Ruiz, and O'Neill (2003) showed that the TPB adequately accounted for variability in condom use intentions among Caucasian and African American incarcerated adults but not among Hispanics. Further, TPB constructs were poor predictors of needle-sharing intentions among any of the incarcerated adults in the authors' sample (Bryan et al., 2003).
The model in Figure 1 has been tested in a sample of incarcerated, sexually experienced, male adolescents (Bryan et al., 2004). In that study, the authors showed strong relationships among model constructs and found that the model constructs accounted for a significant proportion of the variance $(51 \%)$ in intentions. Though this study showed support for the authors' model, it was limited in that the data were cross-sectional, so the authors could not use the model variables to predict behavior prospectively.

In the current study, we proposed to use a model of health behavior that has been shown to predict condom use intentions among criminally involved high-risk adolescents (Bryan et al., 2004) as the basis for testing hypotheses regarding distal effects of alcohol use on the development of intentions to use condoms and on the relationship of those intentions to behavior. Note that by distal and proximal in this discussion, we refer to the context of our theoretical model, not the larger social context. There are currently no comprehensive, individual-level models of safer sexual intentions or behavior tailored to a criminally involved adolescent population reported in the literature. In addition, we were able to find only one empirical study that examined whether alcohol use affected the relationships in a TPB model of condom use behavior (Conner, Graham, \& Moore, 1999). Although this study found that alcohol use did not moderate TPB relationships, Conner et al. (1999) used only hypothetical condom use scenarios, not actual self-reported condom use, and conducted their study with predominantly Caucasian college students. We hypothesized that the structural paths in the model (i.e., from self-efficacy to intentions or from attitudes to intentions) may be weaker among alcohol-using high-risk adolescents and stronger among alcohol abstainers. We further hypothesize that the use of alcohol may consistently interfere with the intention-behavior link such that even adolescents with strong intentions to use condoms may not do so in the presence of alcohol use. A better understanding of these effects of alcohol use on condom use intentions and behavior may shed light on inconsistent findings associated with the study of alcohol's more proximal effects.

\section{Method}

\section{Participants}

Time 1 data were collected from 300 adolescents (77\% male, 23\% female) who were involved with the Denver, Colorado, metro-area juvenile justice system. The gender breakdown reflects the demographics of the Colorado juvenile justice system. The mean age of participants was 15.3 years, and participants ranged in age from 12 to 18 . Over three fourths of participants $(77 \%, n=230)$ reported having had sexual intercourse, and of these, $61(27 \%)$ were female and $169(73 \%)$ were male. In terms of frequency of intercourse, $20 \%$ of participants reported having sex a few times a year, $23 \%$ had sex once a month, $18 \%$ had sex once a week, $23 \%$ had sex two to three times a week, $10 \%$ had sex four to five times a week, and $7 \%$ had sex almost every day. Among those who reported having had sexual intercourse at least once, average age at first intercourse was 13 and median number of lifetime sexual partners was 5 (range, 1-100).

The sample was ethnically diverse: $49 \%$ Hispanic, 23\% Caucasian, $21 \%$ African American, just over 5\% Native American, 1\% Asian or Pacific Islander, and less than $1 \%$ other. Only $35 \%$ of the participants reported living with both of their parents, $40 \%$ reported living with only their mothers, $9 \%$ reported living with only their fathers, $6 \%$ reported living with just a guardian, and $10 \%$ reported living in some other type of 
arrangement. Most participants were still in school (82.6\%), with the mean grade level of 9.5. Just under $9 \%$ of female adolescents and $6.5 \%$ of male adolescents reported having at least one child. This sample ranged from first-time offenders to repeat offenders, and probation sentences for those currently on probation varied from just a few months to several years, with 12 months as the mean number of months on probation. The most frequently cited offenses were possession of a controlled substance (11.6\%), stealing/theft (20\%), auto theft (8.8\%), and assault/fighting (14.9\%).

\section{Design and Procedures}

Recruitment and questionnaire procedures. Recruitment was accomplished in three ways: (a) A trained research assistant maintained a presence in the waiting room of the busiest probation office (Denver, $\mathrm{CO}$ ) and asked youth waiting to see their probation officers if they would be interested in participating; (b) posters were hung in other probation offices, and probation officers maintained a sign-up sheet for interested young people who inquired about the study (these people then completed the study at a time and location convenient for them); and (c) youth center staff asked young people who had prior or current involvement with the criminal justice system if they would be interested in participating. The Denver, Colorado, office was the only location for which we have solid data regarding refusals to participate: $27 \%$ of the adolescents we approached refused to take part in the study. The most common reason given was "Just not interested." Research staff also had to turn down 11 adolescents because they were over 18 . All data should be interpreted with caution given that this is a convenience sample of adolescent volunteers.

Administration of the questionnaires took place at the probation offices, courts, treatment facilities, and youth center. All questionnaires were administered by trained research personnel in private locations without the presence of probation officers, treatment providers, or youth center staff. Research staff members were present to answer any questions and help any adolescent who needed assistance or had trouble reading. All participants had both signed parental/guardian consent and given their assent to par- ticipate. Participants were told that if any question was too personal, they could skip that question, and that if they were unsure of the meaning of a question, they should stop and ask. Participants were assured that their answers were completely confidential and would not be shared with probation officers, youth center staff, or parents. All adolescents who completed surveys were given $\$ 15$ for their participation in the baseline session. All procedures were approved by the University of Colorado at Boulder human subjects review board, and a federal certificate of confidentiality was obtained for this research to further protect participants' privacy.

Time 1 procedure and measures. Participants were given selfadministered paper-and-pencil questionnaires that assessed a range of psychological, behavioral, and sociodemographic variables. Each of the model constructs in Figure 1 was also assessed, as was previous sexual history. Descriptions of the measures of model constructs can be found in Table 1.

Previous condom use was assessed with one question: "How much of the time have you used condoms when you have had sexual intercourse?" A Likert scale ranging from 1 (never) to 5 (always) was used to score responses.

Alcohol problems were assessed with the Rutgers Alcohol Problem Index (RAPI; White \& Labouvie, 1989), a 23-item scale addressing alcohol-related behaviors. The instructions read, "How many times did the following happen to you while you were drinking alcohol or because of your alcohol use during the last year?" Items included the following: "Got into fights, acted bad, or did mean things," and "Went to work or school high or drunk." Response options ranged from 1 (never) to 5 (more than 10 times). RAPI scores were the mean of 23 items; thus, higher scores reflect higher alcohol problems, $\alpha=.93$. Participants who did not use alcohol at all were assigned the lowest possible RAPI score of 23 . The mean RAPI score was $40.94(S D=18.21)$.

Other drug use was measured for marijuana, crystal methamphetamine, and cocaine and crack. Three percent of participants were current crystal

Table 1

Measured Constructs, Source of Items, Coefficient Alpha ( $\alpha)$, and Sample Items

\begin{tabular}{|c|c|c|c|c|}
\hline Construct name & Item & Source & $\alpha$ & Sample item \\
\hline \multicolumn{5}{|l|}{ Positive outlook } \\
\hline Self-esteem & 8 & Rosenberg (1965) & .77 & I feel that I have a number of good qualities. \\
\hline Control over the future & 7 & Whitaker et al. (2000) & .73 & My future is what I make of it. \\
\hline Optimism about the future & 4 & Bryan et al. (2004) & .74 & $\begin{array}{l}\text { How likely do you think it is that you will get a good } \\
\text { job someday? }\end{array}$ \\
\hline \multicolumn{5}{|l|}{ General attitudes } \\
\hline Perceived benefits of condom use & 8 & Bryan et al. (2004) & .88 & $\begin{array}{l}\text { I think condoms are effective at keeping people from } \\
\text { getting AIDS. }\end{array}$ \\
\hline Affective attitudes toward condom use & 4 & Bryan et al. (2004) & .65 & Condoms can ruin the sexual mood (reversed). \\
\hline Peer norms & 4 & Bryan et al. (2004) & .78 & $\begin{array}{l}\text { Most of my friends think people should use condoms } \\
\text { whenever they have sex, even with a steady } \\
\text { partner. }\end{array}$ \\
\hline Condom use self-efficacy & 16 & Brien et al. (1994) & .86 & \\
\hline Obtaining condoms & 2 & Brien et al. (1994) & .70 & $\begin{array}{l}\text { I am confident that I could get condoms without } \\
\text { feeling embarrassed. }\end{array}$ \\
\hline Assertiveness in discussing condoms & 3 & Brien et al. (1994) & .81 & I could suggest using condoms even to a new partner. \\
\hline Dealing with partner dissatisfaction & 5 & Brien et al. (1994) & .79 & $\begin{array}{l}\text { If I were to suggest using condoms to a partner, I } \\
\text { would be afraid that he/she would reject me. }\end{array}$ \\
\hline Mechanics of condom use & 3 & Brien et al. (1994) & .82 & $\begin{array}{l}\text { I am confident in my ability to put a condom on } \\
\text { myself or my partner. }\end{array}$ \\
\hline $\begin{array}{l}\text { Using condoms while under the } \\
\text { influence }\end{array}$ & 3 & Brien et al. (1994) & .80 & $\begin{array}{l}\text { I could remember to use condoms even after I have } \\
\text { been drinking. }\end{array}$ \\
\hline Safer sex intentions & 4 & Bryan et al. (2004) & .85 & $\begin{array}{l}\text { How likely is it that you will use a condom every } \\
\text { time you have sexual intercourse in the next six } \\
\text { months? }\end{array}$ \\
\hline
\end{tabular}


methamphetamine users, $13 \%$ were current cocaine or crack users, and less than $25 \%$ of the sample had ever tried these substances. But the majority of participants $(76 \%)$ had tried marijuana, and over one fourth $(27 \%)$ reported being current users. We asked participants to list "any other drugs you use," and these included LSD, mushrooms (psilocybin), ecstasy, GBH, heroin, and ketamine.

Time 2 procedure and measures. Participants were contacted 6 months after they completed the first questionnaire to complete the Time 2 measure. Research staff contacted participants with reminder postcards 1 month prior and via phone beginning approximately 2 weeks prior to their 6-month follow-up due date. Follow-up questionnaire administration was conducted in a number of circumstances: at the participant's current or former probation office, the participant's home, a convenient location for the participant (e.g., a restaurant), or at the youth center. The average number of attempts at scheduling follow-up appointments was 3.75, and the mean length of actual time that elapsed between the first survey and the follow-up was 7.23 months. The final retention rate was $89 \%$, with 267 of the original 300 participants completing the follow-up. Of the follow-ups that were not completed, 1 participant had died; 18 had moved without leaving any forwarding information with their probation officer, social worker, or the research staff; and 14 were "on the run" (i.e., they had stopped seeing their probation officers and had warrants out for their arrest). Of those who completed the follow-up, 2 had moved out of state, 7 were incarcerated, 3 were in out-of-state reform schools, and 1 was in an in-state reform school. Participants who completed the follow-up were given $\$ 50$ remuneration.

Of those 267 participants who completed the follow-up, $76 \%$ of the boys and $85 \%$ of the girls reported having had sex in the past 6 months. For participants reporting having had sex in the past 6 months, the mean number of sexual encounters was 15 . Eighteen percent of the participants reported having had anal sex, and 54\% reported having had oral sex. Of the participants who completed the follow-up, 20 who reported having been virgins at Time 1 had initiated sexual intercourse within the follow-up period. Follow-up condom use was assessed by asking participants how much of the time they used condoms during intercourse in the last 6 months on a Likert scale ranging from 1 (never) to 5 (always). Of the 183 participants who reported having had sexual intercourse in the previous 6 months and had valid data for the condom use items ( 57 girls, 126 boys), $37 \%$ reported always using condoms in the past 6 months, $14 \%$ said they never used condoms, and the rest used condoms inconsistently.

Recent alcohol use was assessed through three questions adapted from White and Labouvie (1989). Frequency was measured with the following item: "In the last 6 months, how often did you consume at least one alcoholic drink?" Answers were given via a scale ranging from 1 (never) to 9 (every day). The mean response was $3.16(S D=2.24)$, which corresponds to once a month. Approximately one third of participants (34\%) reported not drinking at all in the past 6 months, whereas $27 \%$ reported drinking four to five times a month or more. Quantity was measured with the following question: "In the last 6 months, how many drinks did you usually have at one time?" Answers were given on a scale ranging from 1 (none) to 10 (more than 20 drinks). Again, whereas 34\% reported not drinking at all, the mean response on the scale was 3.08 ( $S D=$ 2.18 ), which corresponds to two to three drinks, and $22 \%$ reported drinking seven to nine drinks or more per drinking occasion. To assess frequency of getting drunk, we asked, "In the last 6 months, when you drank alcohol how often did you get drunk?" Answers were reported on a scale ranging from 1 (never) to 5 (always). Less than half of the sample (40\%) reported that they never got drunk, whereas $20 \%$ of the sample reported that they almost always or always got drunk. The three questions were standardized (i.e., $M=0, S D=1$ ) and summed to produce an overall measure of alcohol use, $\alpha=.87$.

Alcohol use during sex was assessed with one question: "In the past 6 months only, how much of the time have you used alcohol when you have had sexual intercourse?" Participants answered on a scale ranging from 1 (never) to 5 (always). Of those who had intercourse during the follow-up period, only $43 \%$ said that they never used alcohol during sex, meaning that fully $57 \%$ of participants used alcohol during sex at least occasionally, with $6 \%$ of participants reporting using alcohol during sex almost always or always.

\section{Results}

The main goals of this study were to test whether alcohol exerts a distal influence on risky sexual behavior by modifying the development of cognitions that are related to intentions to use condoms and to condom use behavior. To accomplish this goal, we estimated a model of condom use intentions among sexually active high-risk youth, assessed the predictive validity of model constructs in relation to subsequent condom use behavior, and determined whether alcohol use influenced relationships among model variables or the relationship of model variables (particularly intentions) to subsequent condom use. Means and standard deviations on all model variables for the full sample appear in Table $1 .{ }^{1}$

\section{Model of Condom Use Intentions}

Consistent with Bryan et al.'s previous work with adolescents (Bryan et al., 2004; Bryan \& Stallings, 2002) and with adolescent research more generally (cf. Loeber \& Keenan, 1994), age was significantly positively correlated with self-esteem; optimism about the future; perceived control over the future; benefits of condom use; the obtaining, mechanics, and assertiveness subscales of condom use self-efficacy; and condom use intentions. To account for these relationships, we adjusted all measures for age by using standard regression procedures (i.e., residual scores were obtained). The correlation matrix for all the age-regressed variables included in modeling is shown in Table 2 for the 230 participants who reported having had sexual intercourse at least once at the baseline assessment. The model in Figure 1 was then estimated by using the age-regressed data, and it exhibited adequate fit to the data, $\chi^{2}(59, N=230)=155.74, p<.001$; comparative fit index $(\mathrm{CFI})=.88$; root-mean-square error of approximation (RMSEA) $=.088 ; 90 \%$ confidence intervals $(\mathrm{CI})$ of the RMSEA $=.07-.11$; standardized root-mean-square residual $(\mathrm{SRMR})=.098$. Standardized parameter estimates and significance levels appear in Figure 1. All hypothesized relationships were supported. Not shown in the figure are two correlated errors between indicators of the self-efficacy latent factor: one between assertiveness and intoxication and one between obtaining condoms and condom use mechanics. The model accounted for $48 \%$ of the variability in condom use intentions. According to Cohen (1988), this represents a large effect size for multivariate models in the social sciences.

\footnotetext{
${ }^{1}$ Complete analyses of differences in model constructs and sexual behavior based on race-ethnicity, gender, and sexual experience status were conducted. There were no differences in sexual experience status or in self-reported condom use as a function of race or gender. In general, Hispanics had more negative attitudes and beliefs than did either African American or Caucasian participants. Despite differences in the cognitive correlates of condom use, there were no race-ethnicity differences on condom use behavior.
} 
Table 2

Correlations Among Age-Regressed Model Variables for Sexually Active Participants $(n=230)$

\begin{tabular}{|c|c|c|c|c|c|c|c|c|c|c|c|c|c|}
\hline Variable & 1 & 2 & 3 & 4 & 5 & 6 & 7 & 8 & 9 & 10 & 11 & 12 & 13 \\
\hline 1. Self-esteem & - & & & & & & & & & & & & \\
\hline 2. Optimism about the future & $.52 * * *$ & - & & & & & & & & & & & \\
\hline 3. Control over the future & $.57 * * *$ & $.59 * * *$ & - & & & & & & & & & & \\
\hline 4. Benefits of condom use & $.14^{*}$ & $.18 * *$ & $.16^{*}$ & - & & & & & & & & & \\
\hline 5. Condom use attitudes & $.15^{*}$ & $.19^{* *}$ & $.28 * * *$ & $.19 * *$ & - & & & & & & & & \\
\hline 6. Obtaining condoms $\mathrm{s}^{\mathrm{a}}$ & $.18 * *$ & $.17 * *$ & .10 & $.36 * * *$ & $.28 * * *$ & - & & & & & & & \\
\hline 7. Condom use mechanics ${ }^{\mathrm{a}}$ & $.16^{*}$ & $.28 * * *$ & $.18^{* *}$ & $.39 * * *$ & $.28 * * *$ & $.70 * * *$ & - & & & & & & \\
\hline 8. Partner dissatisfaction ${ }^{\mathrm{a}}$ & $.19 * *$ & $.18^{* *}$ & $.18 * *$ & .11 & $.16^{*}$ & $.16^{*}$ & .19 ** & - & & & & & \\
\hline 9. Assertiveness ${ }^{\mathrm{a}}$ & $.16^{*}$ & $.20 * *$ & .12 & $.27 * * *$ & $.16^{*}$ & $.42 * * *$ & $.35 * * *$ & $.20 * *$ & - & & & & \\
\hline 10. Intoxication ${ }^{\mathrm{a}}$ & .11 & $.16^{*}$ & $.16^{*}$ & $.18 * *$ & $.30 * * *$ & $.36 * * *$ & $.35 * * *$ & $.23 * * *$ & $.50 * * *$ & - & & & \\
\hline 11. Condom use norms & .11 & .12 & $.13^{*}$ & $.25 * * *$ & $.32 * * *$ & $.23 * * *$ & $.25 * * *$ & .05 & $.26 * * *$ & $.35 * * *$ & - & & \\
\hline 12. Condom use intentions & .09 & $.14^{*}$ & .08 & $.30 * * *$ & $.33 * * *$ & $.47 * * *$ & $.48 * * *$ & .05 & $.29 * * *$ & $.42 * * *$ & $.42 * * *$ & - & \\
\hline 13. \% use of condoms & .10 & .11 & $.17 * *$ & $.14 *$ & $42 * * *$ & $.30 * * *$ & $.29 * * *$ & .10 & $.22 * *$ & $.41 * * *$ & $.42 * * *$ & $.52 * * *$ & - \\
\hline$M$ & 3.28 & 3.47 & 3.28 & 3.47 & 2.86 & 3.34 & 3.47 & 3.11 & 3.29 & 3.21 & 3.08 & 3.08 & 3.95 \\
\hline$S D$ & 0.52 & 0.46 & 0.53 & 0.70 & 0.75 & 0.84 & 0.73 & 0.80 & 0.83 & 0.86 & 0.78 & 0.83 & 1.04 \\
\hline
\end{tabular}

Note. Range for all variables except condom use is $1-4$. Range for condom use is $1-5$, and this variable only includes those who reported ever having sexual intercourse $(n=230)$.

${ }^{a}$ Variable is a factor of the Condom Use Self-Efficacy Scale (Brien et al., 1994).

$* p<.05 . \quad * * p<.01 . \quad * * * p<.001$.

In order to test the predictive validity of the model constructs on condom use, we regressed Time 2 condom use on all Time 1 measures of model constructs (future orientation, optimism about the future, self-esteem, benefits, attitudes, norms, the overall selfefficacy scale, and intentions). Given the influence of age on these variables, we chose to use the age-regressed data in the regression analysis. We hypothesized that intentions and perhaps self-efficacy would remain as significant predictors of Time 2 condom use, whereas all other model variables would show nonsignificant relationships to condom use because their effects are assumed to be mediated by intentions. The overall regression model accounted for $11 \%$ of the variance in condom use behavior. Consistent with our hypotheses, initial intentions were a significant predictor of condom use 6 months later $\left(B=.19, p<.05, p r^{2}=.03\right)$. We find it interesting that affective attitudes toward condom use were also a significant predictor of condom use 6 months later $(B=.24, p<$ $\left..01, p r^{2}=.04\right)$. No other predictors in the model were significant, indicating that their effects on condom use accrued indirectly through their associations with attitudes and/or intentions.

\section{Influence of Substance Use on Model Relationships}

We examined whether drinking alcohol in the prior 6 months changed the relationships among model variables. To accomplish this test, we separated the sample into two groups: those that reported drinking no alcohol in the prior 6 months at baseline $(n=$ 71) and those that drank at least once in the prior 6 months $(n=$ 157). A cross-groups model (Aiken, Stein, \& Bentler, 1994; Bentler, 1995) was then estimated in EQS Version 6.1 (Bentler \& $\mathrm{Wu}, 2003)$ such that the exact model in Figure 1 was simultaneously estimated in drinkers versus nondrinkers. The initial model constrained all structural paths, loadings on the latent variables, and covariances to be equal in the two groups. The fit of this model was marginal, $\chi^{2}(134, N=228)=279.35, p<.001 ; \mathrm{CFI}=$ .83 ; $\mathrm{RMSEA}=.069 ; 90 \% \mathrm{CI}=.06-.08 ; \mathrm{SRMR}=.13$. In addition, LaGrange multiplier statistics (MacCallum, 1995) suggested three parameters on which the two groups significantly differed. These three parameters were freely estimated in a second model, and a three-degree-of-freedom chi-square test of change in fit $\left(\chi_{\Delta}^{2}\right.$; Hayduk, 1987) was conducted. A significant change in chi-square confirms that the paths tested are significantly different in the two groups, and the change in chi-square was significant in this case, $\chi^{2}{ }_{\Delta}(3, N=228)=19.97, p<.001$. In addition, the overall model fit with these paths freed was adequate, $\chi^{2}(131, N=$ $228)=259.38, p<.001 ; \mathrm{CFI}=.85 ; \mathrm{RMSEA}=.066 ; 90 \% \mathrm{CI}=$ $.05-.08 ;$ SRMR $=.12$.

One path that differed was the correlation between the errors of two of the self-efficacy variables: assertiveness for condom use and using condoms while intoxicated. This correlation was nonsignificant for drinkers $(B=.052)$ but was significant for nondrinkers $(B=.528, p<.001)$. Next, the loading of the assertiveness item on the self-efficacy construct was different in the two groups. The loading was strong and significant for drinkers $(B=$ $.72, p<.001)$ but was nonsignificant for nondrinkers $(B=.20)$. Finally, the relationship between prior condom use and perceived normative support for condom use differed in the two groups, but only slightly. For both groups, the path was positive and significant, but it was slightly stronger for the drinking group $(B=.48$, $p<.001)$ than for the nondrinkers $(B=.32, p<.01)$. The findings for the self-efficacy factor suggest a potentially different condom use self-efficacy factor structure for drinkers versus abstainers. But the main structural relationships hypothesized in the model largely remain the same. One other difference is that the overall model accounted for slightly more of the variance in condom use intentions among nondrinkers ( $52 \%$ of the variance accounted for) than among drinkers (46\% of the variance accounted for). Though this difference is not large, it is consistent with our hypothesis that a rational cognitive model might better account for variability in condom use intentions among nondrinkers than among drinkers. 
Having established that intentions and attitudes were significant, direct, prospective predictors of condom use behavior, we next sought to test as a possible distal effect of alcohol on condom use whether the use of alcohol concurrent with sexual activity interfered with the link between cognitive correlates of condom use and condom use behavior. We used two classes of variables for this analysis. First, we examined whether quantity and frequency of alcohol use moderated either the attitude-behavior or intentionbehavior relationship. Second, we examined whether alcohol use during sexual activity moderated either of these relationships. Both alcohol use variables were taken from the Time 2 assessment, and questions referred to behavior in the previous 6 months, the same time frame as the condom use question. Both alcohol quantity and frequency of use and alcohol use during sex were retained as continuous variables in these analyses. First, all continuous predictors were centered (cf. Aiken \& West, 1991); then, interaction terms were computed as the multiplicative term of a centered alcohol use variable and a centered cognitive correlate.

In the first model, Time 2 condom use was regressed on continuous measures of intentions, attitudes, alcohol quantity and frequency of use, the interaction of alcohol use and intentions, and the interaction of alcohol use and attitudes. The full model accounted for $15 \%$ of the variance in condom use, and as with the original model, both attitudes and intentions were significant predictors of condom use. However, alcohol quantity and frequency of use was not a significant predictor of condom use, nor did it moderate the main effects of attitudes and intentions. In fact, the addition of the alcohol-related set of predictors (alcohol use, the Alcohol Use $\times$ Intentions interaction, and the Alcohol Use $\times$ Attitudes interaction) did not cause a significant change in variance accounted for by the model, $R^{2}{ }_{\Delta}=.002, F(3,149)<1, n s$.

In the second model, we used a more focused measure of alcohol use that specifically asked about alcohol use concurrent with sexual intercourse. In this analysis, Time 2 condom use was regressed on intentions, attitudes, use of alcohol during sex, the interaction of alcohol use and intentions, and the interaction of alcohol use and attitudes. This full model accounted for $16 \%$ of the variance in condom use, and again both attitudes and intentions were significant predictors of condom use. Use of alcohol during sex was not a significant predictor of condom use, nor did it moderate the main effects of attitudes and intentions. The addition of this set of predictors (alcohol use during sex, the Alcohol Use During Sex $\times$ Intentions interaction, and the Alcohol Use During Sex $\times$ Attitudes interaction) did not cause a significant change in variance accounted for by the model, $R^{2}{ }_{\Delta}=.003, F(3,141)<1, n s$.

To assure that we had exhausted all possibilities for the role of alcohol use as a moderator, we created a second alcohol quantity and frequency of use index by multiplying the frequency of drinking by the average number of drinks per drinking occasion participants reported. The results of this analysis were the same as for the overall alcohol use index and the alcohol use during sex measure; there were no direct or moderating effects of alcohol use. Finally, we included our continuous measure of alcohol problems in the model instead of alcohol use and again found that attitudes and intentions remained significant predictors of condom use, whereas alcohol problems had neither a direct nor moderated relationship to condom use. These analyses indicated that there was no direct relationship between alcohol use during the prior 6 months either generally or during intercourse and condom use over that same time frame. In addition, alcohol use did not seem to interfere with the significant relationships of condom use attitudes and intentions and condom use behavior.

Because of the high prevalence of marijuana experience and use in this sample of young people, we repeated our regression analyses by substituting current marijuana use for alcohol use in the regression equations. The results were the same; there was no relationship of marijuana use to condom use, marijuana use did not moderate the relationship of intentions and attitudes to condom use, and intentions and attitudes were still significant predictors of condom use even after accounting for current marijuana use.

\section{Discussion}

The goal of this project was to examine a potential distal role for alcohol use in the prediction of risky sexual behavior. We replicated a model of condom use intentions among criminally involved adolescents and asked whether the relationships among model constructs were the same for adolescents who drink alcohol versus those who abstain. We further asked whether alcohol use concurrent with sexual activity appeared to disrupt a significant condom use intention-behavior link. Our findings highlight the difficulty of solidifying the relationship of alcohol use to risky sexual behavior. Whether these adolescents used alcohol did not change the relationships among model constructs appreciably, and this finding is consistent with the work of Conner et al. (1999) in a completely different population. Further, neither frequency nor quantity of alcohol use, alcohol problems, or marijuana use disturbed the relationship of condom use attitudes and intentions to behavior.

On the one hand, these null results are disappointing from the perspective of gaining a basic understanding of the role of alcohol or substance use in risky sex. On the other hand, these results are somewhat encouraging from the perspective of intervention development. They suggest that intervention content based on the assumption that self-esteem, positive orientation toward the future, attitudes, norms, and self-efficacy are related to condom use intentions need not be altered whether the participants in the intervention are drinkers or not. We do not mean to imply that intervention content should ignore alcohol use generally or the drinking status of participants specifically (see below) but that the more general condom promotion content of the intervention can remain consistent.

We began this research on the basis of our analysis of the literature that there had been little examination of any role for alcohol use in risky sex other than at the time of sexual activity. Our findings join with Conner et al. (1999) to support the idea that this may indeed be the only role that alcohol plays. These findings lead us to the conclusion that has been reached by others in this research area (e.g., Leigh \& Stall, 1993; Weinhardt \& Carey, 2000) that perhaps the role of alcohol is more fruitfully examined at the event level. This is actually the focus of a separate set of analyses arising from this same study. In this forthcoming work (Bryan \& Cooper, 2004), the authors analyze the event-level relationship of alcohol as well as sex-related alcohol expectancies to condom use and have some preliminary evidence that this is where the effect of alcohol on risky sex can be reliably seen in this population. The 
presentation of these results was beyond the scope of our interests in this article.

Though our hypotheses regarding a distal role for alcohol use were not borne out, in other ways our results were quite encouraging. We supported the validity of our model of condom use intentions and suggest that HIV/STD prevention interventions that incorporate constructs in the model (e.g., perceived benefits of and affective attitudes toward condom use, peer norms regarding condom use, and condom use self-efficacy) should successfully increase condom use intentions and behavior. The results also raise the intriguing possibility that targeting more general constructs, including self-esteem, control over the future, and optimism about the future, may bolster condom use self-efficacy among high-risk adolescents. Consistent with the TPB, we found that intentions are a significant prospective predictor of behavior.

An unexpected finding was the direct relationship between affective attitudes toward condoms and condom use behavior 6 months later. Models of behavior such as the TRA/TPB grew out of work that sought to explain why it was that attitude was not a better predictor of behavior. Decades of work finding inconsistent or absent attitude-behavior relationships led to the development of more complex models of the role of attitudes in the prediction of behavior, chief among them the TRA/TPB. Recent work on these models has examined the circumstances under which attitude is expected to be a better or worse predictor of behavior directly (i.e., not mediated through intentions). Conner, Povey, Sparks, James, and Shepherd (2003) recently reviewed the literature on attitudinal ambivalence and conducted an empirical test of the notion put forward by their group and others that when attitudinal ambivalence is high (i.e., "simultaneously evaluating the attitude object in a positive and negative way"; Conner et al., 2003, p. 77), it is a poor direct predictor of intention and behavior. But when individuals are not ambivalent, attitudes should be a strong direct predictor of behavior, even in the presence of a significant relationship to intentions.

Given that we demonstrate the exact pattern of findings that Conner et al. (2003) and others (Armitage \& Conner, 2000; M. Moore, 1980) have described for situations in which ambivalence is low, we suspect that perhaps these adolescents' attitudes about condom use are not characterized by much ambivalence. Whereas older adolescents or adults might be able to simultaneously see both strong positive (disease prevention, birth control) and strong negative (interruption, embarrassment) beliefs that then characterize their attitudes toward condom use, it may be that younger adolescents are more likely to have simpler, more clear-cut, goodversus-bad feelings about condoms. It might also be a phenomenon associated with this particular type of adolescent (impulsive, risk taking), who might be more likely to engage in the absolutist thinking associated with strong positive or strong negative attitudes. Indeed, and consistent with prior research (Devieux et al., 2002), the correlation between a measure of impulsivity (Zuckerman, Kuhlman, Joireman, \& Teta, 1993) and condom attitudes in this sample was negative and significant $(r=-.20, p<.001)$. Unfortunately, we do not have the necessary measures to assess level of ambivalence in our sample, so this explanation is speculative. But it is consistent with prior theorizing and empirical work on the attitude-behavior relationship as well as the developmental stage and personality characteristics of our population.
A limitation of our research is that our conclusions are based on paper-and-pencil self-reporting from adolescents, and thus we suggest caution in the interpretation of our findings. In our current intervention research, we have incorporated audio computerassisted self-interview data collection technology. We expect that this technology will greatly enhance the reliability of our data in future studies with this population and recommend this technology to others interested in working with criminally involved populations, for whom literacy is often a problem. Also, though the causal connections we hypothesize in the model of condom use intentions are supported by theory (the TPB) as well as empirical data in this area (e.g., Bryan et al., 1996), we note that causal conclusions cannot be confidently drawn in studies in which all variables in the model are measured at the same time. It is possible that a different ordering of the variables in the model might fit the data just as well.

In our analysis of general condom use, we did not differentiate the nature of the sexual relationship between the partners (e.g., casual vs. serious). It is possible that partner type would influence both condom use intentions and behavior (Katz, Fortenberry, Zimet, Blythe, \& Orr, 2000; S. M. Moore \& Rosenthal, 1998). Finally, although it is our belief that adolescents involved in the criminal justice system are an important subpopulation for the development of theory-based, empirically targeted HIV/STD prevention interventions, we cannot guarantee that our findings regarding the model of condom use intentions or the relationship of alcohol to risky sex would generalize to noncriminally involved adolescents. For this reason, we encourage preliminary work on the validation of such models in any new population and for any new behavior.

In sum, we have shown that alcohol use by criminally involved adolescents does not influence the relationships among selfesteem, positive orientation to the future, attitudes, norms, selfefficacy, and intentions to use condoms. Further, alcohol use does not seem to moderate the relationship of intentions to use condoms and condom use behavior. This work therefore suggests a focus on more promising levels of analysis of the alcohol-risky sex relationship, particularly at the level of the sexual event. From a broader perspective, we provided support for a theoretical conceptualization of the correlates of condom use intentions and behavior based on model tailoring, that is, the development and testing of theoretical models that include both established predictors of health behavior and constructs relevant to particular subpopulations (cf. Bryan et al., 1997, 2001, 2004). We have provided evidence for the validity of this high-risk-adolescent model of condom use intentions and have shown that model constructs assessed at baseline, particularly affective attitudes about condoms and intentions, predict condom use behavior 6 months later in a manner consistent with our hypotheses. Our work supports the use of such a model in the design of interventions to increase safer sexual behavior among high-risk adolescents.

\section{References}

Aiken, L. S., Stein, J. A., \& Bentler, P. M. (1994). Structural equation analyses of clinical subpopulation differences and comparative treatment outcomes: Characterizing the daily lives of drug addicts. Journal of Consulting and Clinical Psychology, 62, 488-499. 
Aiken, L. S., \& West, S. G. (1991). Multiple regression: Testing and interpreting interactions. Newbury Park, CA: Sage.

Ajzen, I., \& Madden, T. (1986). Prediction of goal-directed behavior: Attitudes, intentions, and perceived behavioral control. Journal of Experimental Social Psychology, 22, 453-474.

Armitage, C. J., \& Conner, M. (2000). The effects of ambivalence on attitude stability and pliability, prediction of behavior, and information processing. Personality and Social Psychology Bulletin, 26, 1432-1443.

Bandura, A. (1992). A social cognitive approach to the exercise of control over AIDS infection. In R. J. DiClemente (Ed.), Adolescents and AIDS: A generation in jeopardy (pp. 89-116). Newbury Park, CA: Sage.

Barthlow, D. J., Horan, P. F., DiClemente, R. J., \& Lanier, M. M. (1995). Correlates of condom use among incarcerated adolescents in a rural state. Criminal Justice and Behavior, 22, 295-306.

Bentler, P. M. (1995). EQS: Structural equations program manual [Computer manual]. Encino, CA: Multivariate Software.

Bentler, P. M., \& Wu, E. J. (2003). EQS 6.1 for Windows Beta Build 65 [Computer software]. Encino, CA: Multivariate Software.

Brien, T. M., Thombs, D. L., Mahoney, C. A., \& Wallnau, L. (1994). Dimensions of self-efficacy among three distinct groups of condom users. Journal of American College Health, 42, 167-174.

Brook, J. S., Balka, E. B., Abernathy, T., \& Hamburg, B. A. (1994). Sequence of sexual behavior and its relationship to other problem behaviors in African American and Puerto Rican adolescents. The Journal of Genetic Psychology, 155, 107-114.

Bryan, A. D., Aiken, L. S., \& West, S. G. (1996). Increasing condom use: Evaluation of a theory-based intervention to decrease sexually transmitted disease in women. Health Psychology, 15, 371-382.

Bryan, A. D., Aiken, L. S., \& West, S. G. (1997). Young women's condom use: The influence of responsibility for sexuality, control over the sexual encounter, and perceived susceptibility to common STDs. Health Psychology, 16, 468-479.

Bryan, A., Aiken, L. S., \& West, S. G. (2004). HIV/STD risk among incarcerated adolescents: Optimism about the future and self esteem as predictors of condom use self-efficacy. Journal of Applied Social Psychology, 34, 912-936.

Bryan, A., \& Cooper, M. L. (2004). Alcohol use and risky sexual behavior among high-risk adolescents: A prospective analysis. Manuscript in preparation.

Bryan, A., Ruiz, M. A., \& O'Neill, D. (2003). HIV-related behaviors among prison inmates: A theory of planned behavior analysis. Journal of Applied Social Psychology, 33, 2565-2586.

Bryan, A. D., Schindeldecker, M. S., \& Aiken, L. S. (2001). Sexual self-control and male condom-use outcome beliefs: Predicting heterosexual men's condom use. Journal of Applied Social Psychology, 31, 1911-1938.

Bryan, A., \& Stallings, M. C. (2002). A case control study of adolescent risky sexual behavior and its relationship to personality dimensions, conduct disorder, and substance use. Journal of Youth and Adolescence, 31, 387-396.

Canterbury, R. J., Clavet, G. J., McGarvey, E. L., \& Koopman, C. (1998). HIV risk-related attitudes and behaviors of incarcerated adolescents: Implications for public school students. The High School Journal, 82, $1-10$.

Centers for Disease Control and Prevention. (2000a). Tracking the hidden epidemic: Trends in STDs in the United States 2000. Retrieved January 17, 2001, from http://www.cdc.gov/hiv/pubs/facts/youth.htm

Centers for Disease Control and Prevention. (2000b). Young people at risk: HIV/AIDS among America's youth.. Retrieved January 16, 2002, from http://www.cdc.gov/nccdphp/dash/rtc/hiv-curric.htm

Cohen, J. (1988). Statistical power analyses for the behavioral sciences (2nd ed.). Hillsdale, NJ: Erlbaum.

Conner, M., Graham, S., \& Moore, B. (1999). Alcohol and intentions to use condoms: Applying the theory of planned behaviour. Psychology and Health, 14, 795-812.

Conner, M., Povey, R., Sparks, P., James, R., \& Shepherd, R. (2003). Moderating role of attitudinal ambivalence within the theory of planned behaviour. British Journal of Social Psychology, 42, 75-94.

Dermen, K. H., Cooper, M. L., \& Agocha, V. B. (1998). Sex-related alcohol expectancies as moderators of the relationship between alcohol use and risky sex in adolescents. Journal of Studies on Alcohol, 59, $71-77$.

Devieux, J., Malow, R., Stein, J. A., Jennings, T. E., Lucenko, B. A., Averhart, C., \& Kalichman, S. (2002). Impulsivity and HIV risk among adjudicated alcohol- and other drug-abusing adolescent offenders. AIDS Education \& Prevention, 14, 24-35.

DiClemente, R. J. (1992). Psychosocial determinants of condom use among adolescents. In R. J. DiClemente (Ed.), Adolescents and AIDS: A generation in jeopardy (pp. 34-51). Newbury Park, CA: Sage.

Donovan, C., \& McEwan, R. (1995). A review of the literature examining the relationship between alcohol use and HIV-related sexual risk-taking in young people. Addiction, 90, 319-328.

Fazekas, A., Senn, C. Y., \& Ledgerwood, D. M. (2001). Predictors of intention to use condoms among university women: An application and extension of the theory of planned behavior. Canadian Journal of Behavioral Science, 33, 103-117.

Halpern-Felsher, B. L., Millstein, S. G., \& Ellen, J. M. (1996). Relationship of alcohol use and risky sexual behavior: A review and analysis of findings. Journal of Adolescent Health, 19, 331-336.

Hayduk, L. A. (1987). Structural equation modeling with LISREL: Essentials and advances. Baltimore: Johns Hopkins University Press.

Hutchinson, M. K., Jemmott, J. B., Jemmott, L. S., Braverman, P., \& Fong, G. T. (2003). The role of mother-daughter sexual risk communication in reducing sexual risk behaviors among urban adolescent females: A prospective study. Journal of Adolescent Health, 33, 98-107.

Katz, B. P., Fortenberry, J. D., Zimet, G. D., Blythe, M. J., \& Orr, D. P. (2000). Partner-specific relationship characteristics and condom use among young people with sexually transmitted diseases. Journal of Sex Research, 37, 69-75.

Koniak-Griffin, D., Lesser, J., Uman, G., \& Nyamathi, A. (2003). Teen pregnancy, motherhood, and unprotected sexual activity. Research in Nursing \& Health, 26, 4-19.

Laraque, D., McLean, D. E., Brown-Peterside, P., Ashton, D., \& Diamond, B. (1997). Predictors of reported condom use in central Harlem youth as conceptualized by the health belief model. Journal of Adolescent Health, $21,318-327$.

Leigh, B. C., \& Stall, R. (1993). Substance abuse and risky sexual behavior for exposure to HIV: Issues in methodology, interpretation, and prevention. American Psychologist, 48, 1035-1045.

Loeber, R., \& Keenan, K. (1994). Interaction between conduct disorder and its comorbid conditions: Effects of age and gender. Clinical Psychology Review, 14, 497-523.

Lowry, R., Holtzman, D., Truman, B. I., Kann, L., Collins, J. L., \& Kolbe, L. J. (1994). Substance use and HIV-related sexual behaviors among U.S. high school students: Are they related? American Journal of Public Health, 84, 1116-1120.

Lux, K. M., \& Petosa, R. (1995). Preventing HIV infection among juvenile delinquents: Educational diagnosis using the health belief model. International Quarterly of Community Health Education, 15, 145-163.

MacCallum, R. C. (1995). Model specification: Procedures, strategies, and related issues. In R. H. Hoyle (Ed.), Structural equation modeling. Concepts, issues, and applications (pp. 16-36). Thousand Oaks, CA: Sage.

Moore, M. (1980). Validation of attitude toward any practice scale through use of ambivalence as a moderator. Educational and Psychological Measurement, 33, 481-483. 
Moore, S. M., \& Rosenthal, D. A. (1998). Contemporary youths' negotiation of romance, love, sex, and sexual disease. In V. C. de Munck (Ed.), Romantic love and sexual behavior: Perspectives from the social sciences (pp. 233-247). Westport, CT: Praeger.

Morris, R. E., Baker, C. J., Valentine, M., \& Pennisi, A. J. (1998). Variations in HIV risk behaviors of incarcerated juveniles during a four-year period: 1989-1992. Journal of Adolescent Health, 23, 39-48.

Rosenberg, M. (1965). Society and the adolescent self-image. Princeton, NJ: Princeton University Press.

Rosengard, C., Adler, N. E., Gurvey, J. E., Dunlop, M. B. V., Tschann, J. M., Millstein, S. G., \& Ellen, J. M. (2001). Protective role of health values in adolescents' future intentions to use condoms. Journal of Adolescent Health, 29, 200-207.

Rosenstock, I. M. (1990). The health belief model: Explaining health behavior through expectancies. In K. Glanz, F. Lewis, \& B. Rimer (Eds.), Health behavior and health education: Theory, research, and practice (pp. 39-62). San Francisco: Jossey-Bass.

Shafer, M. A., Hilton, J. F., Ekstrand, M., Keogh, J., Gee, L., DiGiorgioHaag, L., et al. (1993). Relationship between drug use and sexual behaviors and the occurrence of sexually transmitted diseases among high-risk male youth. Sexually Transmitted Diseases, 20, 307-313.

Smith, B. N., \& Stasson, M. F. (2000). A comparison of health behavior constructs: Social psychological predictors of AIDS-preventive behavioral intentions. Journal of Applied Social Psychology, 30, 443-462.

St. Lawrence, J. S., Crosby, R. A., Belcher, L., Yazdani, N., \& Brasfield, T. L. (1999). Sexual risk reduction and anger management interventions for incarcerated male adolescents: A randomized controlled trial of two interventions. Journal of Sex Education and Therapy, 24, 9-17.

Sutton, S., McVey, D., \& Glanz, A. (1999). A comparative test of the theory of reasoned action and the theory of planned behavior in the prediction of condom use intentions in a national sample of English young people. Health Psychology, 18, 72-81.

Tubman, J. G., \& Langer, L. M. (1995). “About last night”: The social ecology of sexual behavior relative to alcohol use among adolescents and young adults in substance abuse treatment. Journal of Substance Abuse, 7, 449-461.

Weinhardt, L. S., \& Carey, M. P. (2000). Does alcohol lead to sexual risk behavior? Findings from event-level research. Annual Review of Sex Research, 11, 125-157.

Whaley, A. L. (1999). Preventing the high-risk sexual behavior of adolescents: Focus on HIV/AIDS transmission, unintended pregnancy, or both? Journal of Adolescent Health, 24, 376-382.

Whitaker, D. J., Miller, K. S., \& Clark, L. F. (2000). Reconceptualizing adolescent sexual behavior: Beyond did they or didn't they? Family Planning Perspectives, 32, 111-117.

White, H. R., \& Labouvie, E. W. (1989). Towards the assessment of adolescent problem drinking. Journal of Studies on Alcohol, 50, 30-37.

Zuckerman, M., Kuhlman, D. M., Joireman, J., \& Teta, P. (1993). A comparison of three structural models for personality: The Big Three, the Big Five, and the Alternative Five. Journal of Personality and Social Psychology, 65, 757-768. 